\title{
Introduction: an empirical framework for deconstructing the realities of governing marine protected areas
}

P.J.S. Jones ${ }^{1 *}$, E.M. De Santo ${ }^{2}$, W. Qiu ${ }^{1}$ and O. Vestergaard ${ }^{3}$

${ }^{1}$ Department of Geography, University College London, Pearson Building, Gower Street, London, WC1E 6BT United Kingdom

${ }^{2}$ Marine Affairs Program, Dalhousie University, 6100 University Avenue, Suite 5068, PO Box 15000, Halifax, NS B3H 4R2 Canada

${ }^{3}$ Freshwater and Marine Ecosystems Branch, Division for Environmental Policy Implementation, United Nations Environment Programme, Nairobi, Kenya

"Corresponding author. Tel.: +44 2076790528 Email: P.J.Jones@ucl.ac.uk

Synthesis paper for a special issue of Marine Policy: Governing marine protected areas: towards social-ecological resilience through institutional diversity. Editors - De Santo EM, Jones PJS, Qiu W and Clifton J (based on MPA Governance project www.mpag.info)

This is the authors' version of this paper, which is the same as the final published paper. The published version, all rights for which are reserved by Elsevier Ltd, is available at http://dx.doi.org/10.1016/j.marpol.2012.12.025. This authors' version is available here.

\begin{abstract}
Debates surrounding governance strategies for marine protected areas (MPAs) have to date largely focused on top-down, bottom-up or market-based approaches. Whilst co-management approaches for governing MPAs are widely accepted as a way forward for combining these three strategies, many interpretations of this concept exist and it is applied in many different ways in MPAs in different contexts. This study aimed to explore governance through a case-study approach based on a specifically developed empirical framework - the marine protected area governance (MPAG) analysis framework - to increase understanding of how to combine the three governance approaches. A dialogue with MPA practitioners in 20 case studies helped shape the MPAG analysis framework as it developed, and an international workshop was held on 'Governing MPAs', bringing the practitioners together to compare results and further develop the framework. This paper provides an overview of the topic and research methodology and briefly introduces the case studies further explored in this special issue.
\end{abstract}

Key Words: Governance analysis; empirical framework; marine protected areas; co-management

Research Highlights

- Marine Protected Areas represent an interesting context for analysing governance approaches

- Co-management is a context rather than a solution to governance challenges

- Empirical framework is outlined for governance analyses based on combining incentives

- The research focus is the realities of combining top-down and bottom-up approaches

- Twenty case studies to which the empirical framework was applied are introduced

Jones PJS, De Santo EM, Qiu W and Vestergaard O (2013) Introduction: an empirical framework for deconstructing the realities of governing marine protected areas. Marine Policy, 41, pp1-4 doi:10.1016/j.marpol.2012.12.025 1 


\section{Overview of the marine protected area governance (MPAG) project and its theoretical background}

The International Union for Conservation of Nature (IUCN) defines a marine protected area (MPA) as "a clearly defined geographical space, recognised, dedicated and managed, through legal or other effective means, to achieve the long-term conservation of nature with associated ecosystem services and cultural values" [1]. Whilst the international community continues to push for protected area targets, including the Convention on Biological Diversity's target for 10\% of marine areas under national jurisdiction to be protected by the year 2020, a wider and highly important question remains as to whether MPAs are effective in achieving their conservation objectives, and if not, whether and how this failure is related to the way(s) in which they are governed.

Debates on the merits and downfalls of different approaches to governance have evolved with civilisation, and many influential thinkers have put forward arguments concerning the relative importance of top-down (regulation by the state), bottom-up (community-based), and market (economic incentives) approaches. There is a vast literature on the relative merits of these approaches and many definitions of governance. Indeed, the word 'governance' is derived from Plato's use of the Greek verb 'to steer' (The Republic, 360BC), and another way to consider these debates is to examine how different ways of steering human affairs (Table 1) can be combined in order to achieve strategic societal objectives. For the purposes of this project, the following definition of governance was thereby considered most appropriate: "steering human behaviour through combinations of people, state and market incentives in order to achieve strategic objectives". This definition is consistent with the growing recognition in governance debates that there is a need to move beyond ideological arguments as to which approach is 'right' or 'best', and, instead, develop governance models, frameworks and approaches that combine the steering role of states, markets and people [2].

Table 1 Three perspectives on sources of governance steer

\begin{tabular}{|l|l|l|}
\hline $\begin{array}{l}\text { Steer } \\
\text { type }\end{array}$ & Decisions taken by & Characteristics \\
\hline $\begin{array}{l}\text { State } \\
\text { steer }\end{array}$ & $\begin{array}{l}\text { Governments and } \\
\text { regulatory agencies }\end{array}$ & $\begin{array}{l}\text { Top-down decisions by state through laws and } \\
\text { regulations, drawing on expert advice }\end{array}$ \\
\hline $\begin{array}{l}\text { Market } \\
\text { steer }\end{array}$ & $\begin{array}{l}\text { Markets and economic } \\
\text { systems }\end{array}$ & $\begin{array}{l}\text { Decisions on basis of economic rationality through } \\
\text { markets and/or implemented through economic } \\
\text { incentives, including property rights }\end{array}$ \\
\hline $\begin{array}{l}\text { People } \\
\text { steer }\end{array}$ & $\begin{array}{l}\text { Civil society: people, } \\
\text { social networks and } \\
\text { related organizations }\end{array}$ & $\begin{array}{l}\text { Bottom-up decisions through deliberations amongst } \\
\text { individuals, community/non-governmental organizations } \\
\text { and social/family networks }\end{array}$ \\
\hline
\end{tabular}

Many social and political scientists have taken these debates forward through studies of natural resource governance approaches. However, many governance analyses, particularly those from a common-pool resource (CPR) perspective, drawing on neo-institutional theories, remain primarily focused on the role of people and civil society in self-organising social-ecological systems e.g. Ostrom [3], and resistant to the potential role of some degree and form of state coordination, control and/or regulation. This is consistent with Kjær's [4] observation that whilst governance analyses should consider the role of the government and state steer, since the 1980s governance has increasingly been considered by many analysts as being distinct from government in its focus on people and civil society. The research upon which this paper is based aims to move

Jones PJS, De Santo EM, Qiu W and Vestergaard O (2013) Introduction: an empirical framework for deconstructing the realities of governing marine protected areas. Marine Policy, 41, pp1-4 doi:10.1016/j.marpol.2012.12.025 2 
these debates forward through analyses of MPA case studies that are based less on theories and underpinning ideals, and more on the realities of such case studies, including an acceptance of the potential contribution of the state towards addressing the many challenges raised by MPAs in effectively achieving strategic conservation objectives [5].

Collaborative management (hereafter co-management) is a common concept or narrative that is employed in natural resource and protected area governance, whereby local communities and the state work on a partnership basis to sustainably manage natural resource use and/or conserve biodiversity, potentially involving all three of the governance approaches listed above. However, co-management arguably simply serves as a new framing device as to the relative emphasis that should be placed on the three approaches, rather than representing an answer to these debates.

MPAs are an important focus for debates concerning how these different approaches can be combined in co-management. It is widely accepted that co-managing MPAs is the way forward, but there are many different interpretations of this concept and it is applied in many different ways amongst MPAs in different contexts. One way of considering the challenges of comanaging MPAs is to consider the question: what does the recommendation that the "design and management of MPAs must be both top-down and bottom-up" [6] actually mean in practice?

The research upon which this paper draws was conceived to address this question by examining how different governance approaches are combined, through a detailed analysis of a range of MPA case studies. In examining the relative roles of top-down, bottom-up and market approaches to governance in these case studies, this project sought to explore the proposition that these approaches are applicable to different challenges in different contexts, and hence a combination of governance approaches is necessary to effectively achieve strategic conservation objectives.

The initial proposal for this project was circulated amongst the membership of the IUCN World Commission on Protected Areas (WCPA), and a pre-conference workshop was held at the second International Marine Protected Area Congress (IMPAC2) in Washington, DC in May 2009. Prior to the workshop, a governance analysis framework was developed as a proposal for analysing the case studies. This framework (discussed in more detail below) was subsequently refined, both in the light of discussions at the workshop and of feedback received from international MPA practitioners. During 2009-2010, project participants utilised the framework to analyse governance approaches in their case study MPAs, and in October 2010 a case study workshop was held in Lošinj, Croatia, hosted by the Blue World Institute and supported by the United Nations Environment Programme (UNEP). This workshop focused on case study presentations based on applying the analytical framework, and a resulting UNEP technical report based on these analyses was published in 2011 [2].

\section{The MPA Governance Empirical Framework}

This study was developed as a means of systematically analysing and comparing MPA governance in a representative range of case studies from around the world, with a view to identifying 'good practice' and assessing its transferability to other MPAs in comparable contexts. A framework for analysing MPA governance was initially developed by the first author, subject to subsequent refinements in discussion with the other authors, coupled with a review of related literature, including MPA case studies. The framework was further refined and adapted through discussions with MPAG project participants, as described above. The MPA governance analysis framework represents a realist institutional analysis approach. It is realist in that it is designed to collect information and empirically examine case studies in different contexts. It is institutional in that it builds on neo-institutional theories and case studies. Ostrom [7] broadly defines institutions

Jones PJS, De Santo EM, Qiu W and Vestergaard O (2013) Introduction: an empirical framework for deconstructing the realities of governing marine protected areas. Marine Policy, 41, pp1-4 doi:10.1016/j.marpol.2012.12.025 3 
as "prescriptions that humans use to organize all forms of repetitive and structured interactions, including those within families, neighborhoods, markets, firms, sports leagues, churches, private associations, and governments at all scales". We draw on this definition, considering institutions in similarly broad terms as covering a wide range of agreements, interactions, etc., which remain relatively stable over a period of time, including mutually agreed modes of cooperative behavior (norms); interactions through markets (local - distant); government policies and programs; and legal instruments and related obligations.

Certain institutions designed to achieve specific outcomes can be considered as incentives. The analytical framework for this project is based on the concept of such incentives, defined within this context as "institutions that are instrumentally designed to encourage people to choose to behave in a manner that provides for certain strategic policy outcomes, particularly biodiversity conservation objectives, to be fulfilled" [2]. Of course, there are incentives that may encourage people to behave in a manner that undermines the fulfilment of conservation objectives. These could be considered in terms of 'disincentives', but for the purposes of this analysis, the directionality of which is explicitly aligned towards the fulfilment of conservation objectives, such disincentives are discussed in terms of the driving forces that incentives designed to support MPAs must address and withstand [8]. The incentives for MPA governance employed in this analysis were divided into five categories (economic, interpretative, knowledge, legal, and participative) that can be related to the three modes of governance, as outlined in Table 2. It is worth noting that the incentive categories are listed in alphabetical order, i.e. this order does not represent any ranking.

Case study participants examined how different incentives were used and combined to support the effective governance of their MPA, and which particular incentives were needed to make the governance approach more effective. The MPAG framework included several individual incentive types within each category i.e., ten types of economic incentives, four interpretative, five knowledge, eight legal, and six participative. Accordingly, participants assessed their case study MPA employing 33 types of incentives from five categories.

These incentives were assessed in the context of a wider governance analytical framework (Supplementary Material) which was applied to each case study. This provided a structured approach to gathering information on the context of each case study, including certain key socioeconomic metrics, the objectives of the MPA in question, the main drivers and conflicts that need to be addressed, the governance approach, and the effectiveness of the MPA governance approach in terms of fulfilling the MPA's objectives. It is important to recognise that, for the purposes of this MPA governance analysis, effectiveness in achieving the conservation objectives for the MPA was 'the bottom line', i.e. governance processes were evaluated in terms of whether they are effective in achieving conservation outcomes, though other elements of governance, such as equity and stewardship, are also considered as key contributors to effectiveness and included in case study discussions.

Jones PJS, De Santo EM, Qiu W and Vestergaard O (2013) Introduction: an empirical framework for deconstructing the realities of governing marine protected areas. Marine Policy, 41, pp1-4 doi:10.1016/j.marpol.2012.12.025 4 
Table 2 MPAG analytical framework: incentive categories [2]

\begin{tabular}{|l|l|l|}
\hline Incentive category & Definition & Relevant governance mode \\
\hline Economic & $\begin{array}{l}\text { Using economic and property } \\
\text { rights approaches to promote the } \\
\text { fulfilment of MPA objectives. }\end{array}$ & Market-based \\
\hline Interpretative & $\begin{array}{l}\text { Promoting awareness of the } \\
\text { conservation features of the MPA, } \\
\text { the related objectives for } \\
\text { conserving them and the policies } \\
\text { for achieving these objectives, and } \\
\text { promoting support for related } \\
\text { measures. }\end{array}$ & Supporting all three approaches \\
\hline Knowledge & $\begin{array}{l}\text { Respecting and promoting the use } \\
\text { of different sources of knowledge } \\
\text { (local-traditional and expert- } \\
\text { scientific) to better inform MPA } \\
\text { decisions. }\end{array}$ & Supporting all three approaches \\
\hline Legal & $\begin{array}{l}\text { Establishment and enforcement of } \\
\text { relevant laws, regulations etc. as a } \\
\text { source of 'state steer' to promote } \\
\text { compliance with decisions and } \\
\text { thereby the achievement of MPA } \\
\text { obligations }\end{array}$ & Top-down (state steer) \\
\hline Participative & $\begin{array}{l}\text { Providing for users, communities } \\
\text { and other interest groups to } \\
\text { participate in and influence MPA } \\
\text { decision-making that may } \\
\text { potentially affect them in order to } \\
\text { promote their 'ownership' of the } \\
\text { MPA and thereby their potential } \\
\text { to cooperate in the } \\
\text { implementation of decisions. }\end{array}$ & Bottom-up (people steer) \\
\hline
\end{tabular}

Whilst this MPA governance analytical framework includes issues related to participation, equity, etc., it is important to recognise that these analyses were based on the expert views of the contributors to this study, rather than on wider socio-economic studies. The contributors to these case studies included MPA managers and related academic researchers, all of whom had a deep understanding of governance issues in their case studies. Their views may not, however, represent the views of other experts on these case studies or of people who are affected by a given MPA.

\section{Introduction to the Case Studies}

The fifteen case study papers in this special issue are drawn from the total of twenty case studies from around the world (Figure 1) analysed in the MPAG report [2]. They provide examples from a range of governance approaches and contexts, which are discussed further in the following paper [8]. They were both purposively selected, in that certain MPAs considered to be key examples were approached and invited to participate, and self-selected, in that some case studies were proposed to us following the circulation of the initial proposal for this study through the

Jones PJS, De Santo EM, Qiu W and Vestergaard O (2013) Introduction: an empirical framework for deconstructing the realities of governing marine protected areas. Marine Policy, 41, pp1-4 doi:10.1016/j.marpol.2012.12.025 5 
IUCN WCPA and the workshop at IMPAC2. The findings of the analyses of all 20 case studies are discussed in the following paper, and then all but five of these are presented in the 15 case study papers that follow in this special issue. Those case studies that are not included as papers in this special issue are based on the analyses reported in volume 2 of the MPAG technical report [2].

\section{Figure 1 MPA governance case studies [2]}

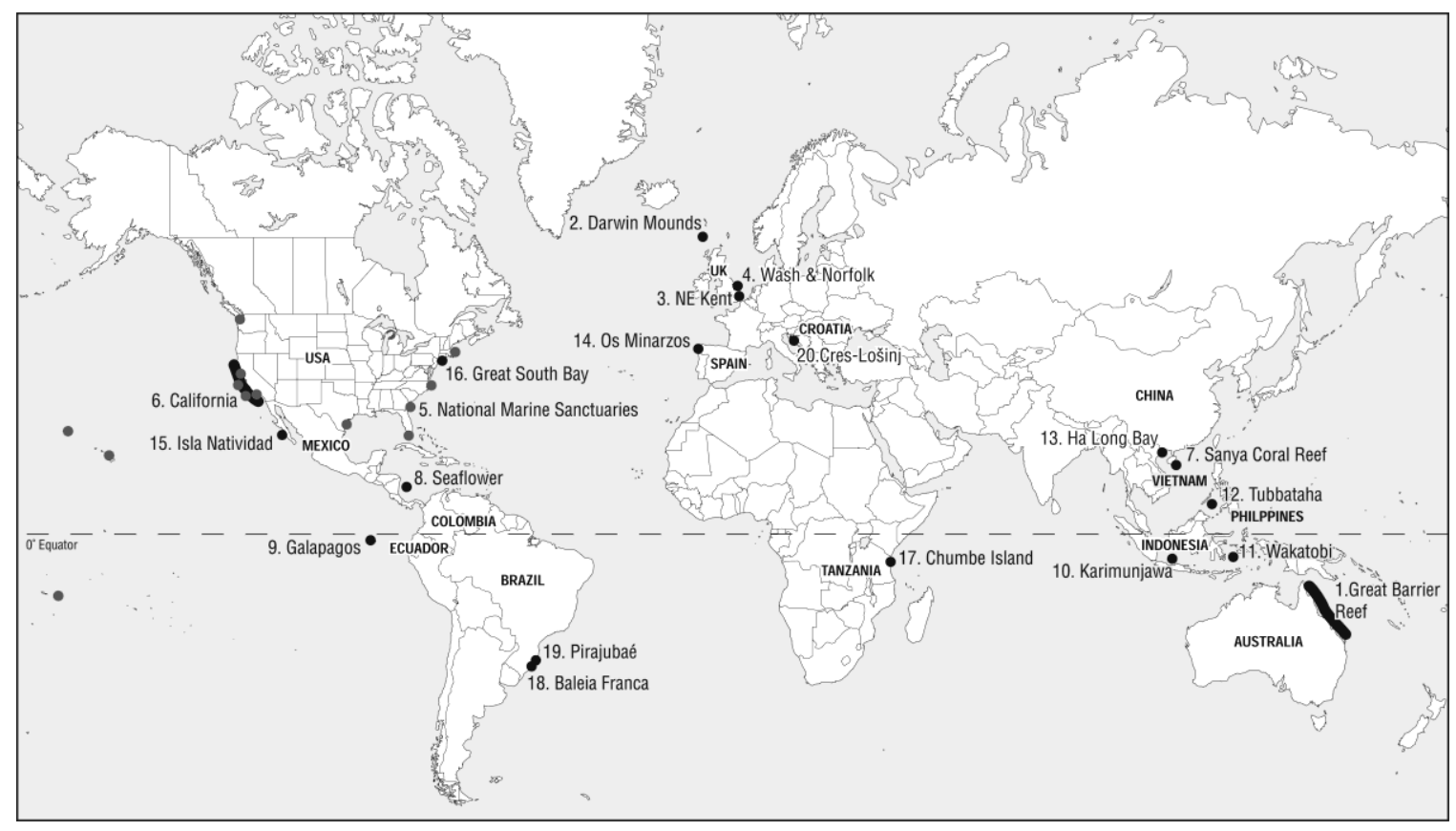

1 Great Barrier Reef Marine Park (Australia); 2 Darwin Mounds Marine Special Area of Conservation; 3 North East Kent European Marine Site; 4 Wash \& North Norfolk Coast European Marine Site (UK); 5 US National Marine Sanctuaries (a network of MPAs with locations shown in grey color); 6 Californian MPAs under the Marine Life Protection Act (US); 7 Sanya Coral Reef National Marine Nature Reserve (China); 8 Seaflower MPA (Colombia); 9 Galápagos Marine Reserve (Ecuador); 10 Karimunjawa Marine National Park; 11 Wakatobi National Park (Indonesia); 12 Tubbataha Reefs Natural Park (Philippines); 13 Ha Long Bay UNESCO World Heritage Site (Vietnam); 14 Os Minarzos Marine Reserve of Fisheries Interest (Spain); 15 Isla Natividad MPA (Mexico); 16 Great South Bay Private Marine Conservation Area (US); 17 Chumbe Island Coral Park (Tanzania); 18: Baleia Franca Environmental Protection Area; 19 Pirajubaé Marine Extractive Reserve (Brazil); 20 Cres-Lošinj Special Zoological Reserve (Croatia)

\section{Acknowledgements}

We are very grateful to all of the participants in the 20 case studies. This research was funded by UNEP (Freshwater and Marine Ecosystems Branch, Division for Environmental Policy Implementation) and we are grateful for their support. Additional contributions were provided by The Blue World Institute of Marine Conservation and Research, which also hosted the workshop, and we are particularly grateful to Dr Peter Mackelworth and his colleagues in this respect. Additional support for the analysis of the findings and production of the report and these papers

Jones PJS, De Santo EM, Qiu W and Vestergaard O (2013) Introduction: an empirical framework for deconstructing the realities of governing marine protected areas. Marine Policy, 41, pp1-4 doi:10.1016/j.marpol.2012.12.025 6 
was also provided by the European Commission through the Framework Programme 7 project

'Monitoring and Evaluation of Spatially Managed Marine Areas' (MESMA, www.mesma.org).

\section{References}

[1] Dudley N. Guidelines for Applying Protected Area Management Categories. Gland, Switzerland: IUCN; 2008.

[2] Jones PJS, Qiu W, De Santo EM. Governing MPAs: getting the balance right. Technical Report to Marine \& Coastal Ecosystems Branch, UNEP, Nairobi; 2011. Available at www.mpag.info

[3] Ostrom E. A general framework for analysing sustainability of social-ecological systems. Science 2009; 325: 419-422.

[4] Kjær AM. Governance. Cambridge, UK: Polity Press; 2004.

[5] Jones PJS. Governing protected areas to fulfil biodiversity conservation obligations: from Habermasian ideals to a more instrumental reality. Environment, Development and Sustainability 2013; 15(1): 39-50

[6] Kelleher G. Guidelines for Marine Protected Areas. Gland, Switzerland: IUCN; 1999.

[7] Ostrom E. Understanding Institutional Diversity. New Jersey: Princeton University Press; 2005.

[8] Jones PJS, Qiu W, De Santo EM. Governing marine protected areas: social-ecological resilience through institutional diversity. Marine Policy 2013; 41, 5-13 


\section{Supplementary Material \\ Framework employed for analyzing MPA governance in individual case studies [2]}

\section{CONTEXT}

A brief overview of the MPA's designation in relation to the socioeconomic and political

situation of the host country.

Name of MPA:

Size of MPA:

Coastline length (where applicable):

Distance from shore:

Population per $\mathrm{km}^{2}$ :

Population growth rate:

Per capita GDP: \$US

This information is often only available at a national level but please give some indication of the economic status of people around the MPA relative to the national economic status - are people around the MPA economically better or worse off than other people in the rest of the country?

GDP growth rate:

GDP composition by sector:

Labor force by occupation:

Unemployment rate:

Government type:

\section{OBJECTIVES}

Briefly describe the MPA's objectives in relation to the legislative obligations/framework under which it was designated.

\section{DRIVERS/CONFLICTS}

What are the main activities that need regulating to achieve the MPA's objectives? e.g. commercial and recreational fishing, tourism, inflowing pollution. What are the trends in these activities and what forces are driving these trends? e.g. incoming fishers, global fish markets, incoming corporate tourism, rising human populations through immigration, intensification of surrounding agriculture / industry, etc.

\section{GOVERNANCE FRAMEWORK/APPROACH}

Describe the governance structure / approach, including examples/stories that illustrate how this is (or is not) effective in addressing the conflicts and fulfilling the biodiversity and resource conservation objectives of the MPA.

Jones PJS, De Santo EM, Qiu W and Vestergaard O (2013) Introduction: an empirical framework for deconstructing the realities of governing marine protected areas. Marine Policy, 41, pp1-4 doi:10.1016/j.marpol.2012.12.025 8 


\section{EFFECTIVENESS}

Discuss whether the management objectives are being fulfilled, particularly the biodiversity and sustainable resource exploitation objectives. Please give your assessment of:

- The proportion of impacts that are being addressed (or not)

- The degree to which they are being addressed (or not)

This is focused on the effectiveness of the MPA governance incentives in addressing impacts from surrounding uses and local and incoming users, recognizing that this enhances ecosystem resilience to wide-scale impacts that are beyond the control of individual MPAs, particularly those related to climate change (e.g. increases in seawater temperature, ocean acidification and sea level rise).

0 No use impacts addressed; designation may even have increased impacts by undermining previous institutions.

1 Some impacts beginning to be slightly addressed.

2 Some impacts partly addressed but some impacts not yet addressed.

3 Some impacts completely addressed, some are partly addressed.

4 Most impacts addressed but some not completely.

5 All impacts from local activities completely addressed.

Please give your assessment / judgment of:

- where your MPA case study currently is on this scale;

- what effect the MPA designation and related governance incentives have had on effectiveness by addressing use impacts;

- the direction that MPA effectiveness is going: recovering (+), declining (-) or stable

This effectiveness assessment captures what can also be considered in terms of implementation and management, but the focus of this analysis is on the effectiveness of particular or combinations of governance incentives.

\section{INCENTIVES}

Summarize the key incentives (employing the five categories) for effective governance, including how you think particular individual or combinations of incentives have been particularly effective. Also discuss how you think governance could be improved to better meet the conservation objectives through improved individual or combinations of incentives. Please refer to the list of incentives below, including some suggestions as to other incentives this section might also include.

\section{KEY ISSUES}

Outline what you think the key governance issues and questions are in relation to this case study. This should draw the analysis together in terms of the current effectiveness of the governance

Jones PJS, De Santo EM, Qiu W and Vestergaard O (2013) Introduction: an empirical framework for deconstructing the realities of governing marine protected areas. Marine Policy, 41, pp1-4 doi:10.1016/j.marpol.2012.12.025 9 
incentives to fulfill the conservation objectives for this MPA case study. Please summarize the key points concerning issues such as:

- which incentives or combinations of incentives are particularly effective for the MPA in question;

- which incentives or combinations of incentives are particularly ineffective;

- the relative role of the different categories of incentives;

- which incentives or combinations of incentives might be or need to be employed to improve the effectiveness of governance, i.e. the potential to better fulfill the biodiversity and resource objectives / obligations of the MPA by better regulating impacting activities and / or addressing the forces that are driving them

\section{List of incentives used in the preliminary case studies (Section 6 of the above analysis framework)}

\section{$\underline{\text { Economic incentives }}$}

Using economic and property rights approaches to promote the fulfillment of MPA objectives, e.g.

1.1 Promoting economically and ecologically sustainable resource exploitation, through spillover effects and enhancing direct and indirect use values from resources

1.2 Green marketing of products and services from the MPA

1.3 Fair sharing of economic costs and benefits, particularly measures to reduce the 'leakage' of the economic benefits of the MPA away from local people, and to ensure that particular groups of people do not reap all the benefits or bear an undue burden of the costs

1.4 Providing economic compensation to restricted users for profits foregone

1.5 Payments for the flow of ecosystem services provided by the MPA

1.6 Allocation or reinforcement of community / user property rights

1.7 Promoting alternative livelihoods

1.8 Improvements in local infrastructure and living standards

1.9 Protection from incoming users

1.10 Funding from state, private or NGO sources to promote the effectiveness of the MPA through the use of various incentives, provided that this funding does not lead to 'institutional capture' - undue influence on MPA governance that undermines the effectiveness of the MPA.

In relation to the other incentives, how important are economic incentives (including property rights) in promoting the effectiveness of the MPA?

In what particular ways might economic incentives be improved to promote the effectiveness of the MPA?

Jones PJS, De Santo EM, Qiu W and Vestergaard O (2013) Introduction: an empirical framework for deconstructing the realities of governing marine protected areas. Marine Policy, 41, pp1-4 


\section{Interpretative incentives}

Promoting a sense of care, ownership, pride and moral / ethical feelings for the marine environment in order to enhance the potential for participation and cooperation, e.g.

2.1 Public communication, education and awareness-raising on the importance / vulnerability of marine ecosystems and the benefits of the MPA e.g. through newsletters, web sites, education programs, media campaigns, etc.

2.2 Role of celebrity 'champions'

2.3 Promoting recognition of the potential benefits from well-managed MPAs, e.g. spillover to surrounding fisheries, enhanced resilience, ecosystem services.

2.4 Public communication, education and awareness-raising on MPA regulations and restrictions, including boundaries

In relation to the other incentives, how important are interpretative incentives in promoting the effectiveness of the MPA?

In what particular ways might interpretative incentives be improved to promote the effectiveness of the MPA?

\section{Knowledge incentives}

Respecting and promoting the use of different knowledges (social and natural / physical) to better inform MPA decisions, e.g.

3.1 Integration of local / traditional / indigenous knowledge in MPA decision-making

3.2 Maximizing scientific knowledge to guide / inform MPA decision-making and monitoring/evaluation

3.3 Promoting mutual respect and collective learning between different knowledge owners (e.g. scientists and local resource users)

3.4 Developing mechanisms for independent advice and / or arbitration in the face of conflicting information and / or uncertainty

3.5 Agreed basis for the role of precautionary approaches in the face of uncertainty

How critical an issue is uncertainty in decision-making processes in relation to this MPA case study?

In relation to the other incentives, how important are knowledge incentives in promoting the effectiveness of the MPA?

In what particular ways might knowledge incentives be improved to promote the effectiveness of the MPA?

Jones PJS, De Santo EM, Qiu W and Vestergaard O (2013) Introduction: an empirical framework for deconstructing the realities of governing marine protected areas. Marine Policy, 41, pp1-4 


\section{Legal incentives}

Use of relevant laws, regulations and rules as a source of 'state steer' to promote compliance and the achievement of MPA objectives / obligations, e.g.

4.1 International / regional / national / local regulatory obligations that require effective MPA conservation, including the potential for top-down interventions

4.2 Clarity and consistency in defining legal objectives of MPAs, general and zonal restrictions, jurisdictional boundaries, roles and responsibilities of different authorities and organizations

4.3 Effective judicial system for penalizing transgressors

4.4 Legal provisions to ensure public rights and transparency in MPA management processes

4.5 Legal or other official basis for cross-sectoral / cross-jurisdictional restrictions to support the achievement of MPA objectives

4.6 Performance standards / conditions / criteria / requirements related to the MPA's conservation objectives and attached to user/property rights, participatory governance structures, etc.

4.7 Scope for flexibility - adaptive management and local discretionary action, Maintaining, building on and working through local customary institutions, provided that this does not undermine the fulfillment of conservation objectives

4.8 Ensuring that sufficient national / local state capacity, political will, surveillance technologies and financial resources are available to enforce all restrictions equitably on all local and incoming users, including addressing driving forces - pressures from immigration, corporate mass tourism, fisheries market forces, etc.

Taking all these factors into account, please give your assessment of the overall effectiveness of the state in steering or controlling MPA governance approaches to promote effectiveness. Does the state sufficiently support the MPA? Or does it passively / actively undermine it?

In relation to the other incentives, how important are legal incentives in promoting the effectiveness of the MPA?

In what particular ways might legal incentives be improved to promote the effectiveness of the MPA?

\section{$\underline{\text { Participative incentives }}$}

Providing opportunities for stakeholders, communities and other interest groups to participate in and influence MPA decision-making that may potentially affect them as a source of 'steer' to ensure good implementation of the decisions made, e.g.

5.1 Participative governance structures and processes such as stakeholder committees, stakeholder consultations, participative GIS planning, etc., including training to support such processes

5.2 Participative enforcement, e.g. peer enforcement, community rangers and wardens etc.

5.3 Building trust / social capital between different actors

5.4 Transparent participation and decision-making processes

5.5 Clear rules on the means and degree of participation from different groups

Jones PJS, De Santo EM, Qiu W and Vestergaard O (2013) Introduction: an empirical framework for deconstructing the realities of governing marine protected areas. Marine Policy, 41, pp1-4

doi:10.1016/j.marpol.2012.12.025 12 
5.6 Bringing in 'neutral' facilitators to facilitate participative processes;

Does the participation of stakeholders support or undermine the MPA?

In relation to the other incentives, how important are participative incentives in promoting the effectiveness of the MPA?

In what particular ways might participative incentives be improved to promote the effectiveness of the MPA?

Jones PJS, De Santo EM, Qiu W and Vestergaard O (2013) Introduction: an empirical framework for deconstructing the realities of governing marine protected areas. Marine Policy, 41, pp1-4 doi:10.1016/j.marpol.2012.12.025 13 